\title{
Measuring public attitudes to severe mental illness in Greece: Development of a new scale
}

\author{
Michael Madianos MD, MPH, PhD*

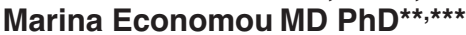 \\ Lily Evangelia Peppou BSc MSc** \\ George Kallergis MD PhD* \\ Efi Rogakou BSc MSc ${ }^{\star * *}$ \\ George Alevizopoulos MD PhD*
}

* Department of Mental Health and

Behavioral Sciences, School of Health

Sciences, University of Athens, Zografou

Community Mental Health Center

** University Mental Health Research

Institute (UMHRI-EPIPSI) Athens

*** Eginition Hospital, Department of Psychiatry, Medical School, University of Athens

GREECE

\footnotetext{
ABSTRACT - Background and Objectives: The purpose of the present study was to develop an attitudinal schedule, the Attitudes to Severe Mental Illness (ASMI) scale, which synthesizes elements from different conceptual frameworks of the field, while addressing gaps on the existing literature on stigma measurement.

Methods: A national representative sample of 2039 adults from the general population was interviewed by telephone.

Results: Factor analysis revealed 4 factors to underlie the data, namely "stereotyping" "optimism", "coping" and "understanding", which explained $67 \%$ of total variance. The instrument's face and predictive validity were also supported, while its internal consistency and test -retest reliability were found to be high for the overall scale and its factors.

Conclusions: Consistent with these, the ASMI scale emerges as a valid and reliable tool for the assessment of attitudes towards severe mental illness, while it opens new directions for advancing scientific understanding of the topic.
} 


\section{Introduction}

Deeply ingrained in social and cultural norms, stigma surrounding mental illness entails prejudicial and rejecting attitudes towards people with psychiatric disorders, which in turn result into corresponding discriminatory acts against them in fundamental areas of life, such as housing, employment and social relationships ${ }^{1-3}$. However, the stigma of mental illness does not stop on people with psychiatric disorders; their family members and the mental health system in general are also adversely influenced by $\mathrm{it}^{4-6}$.

Theoretical formulations about mental illness stigma have contributed significantly to furthering scientific understanding of the phenomenon. Consistent with this, the conceptualization of stigma is based on three prevailing models, that of Corrigan ${ }^{7}$, of Link and Phelan ${ }^{8}$ and of Sartorius 9 . In their model, Corrigan and colleagues have shed light on the cognitive and behavioral aspects of mental illness stigma; namely stereotypes, prejudice and discrimination ${ }^{7}$; while Link and Phelan ${ }^{8}$ have concentrated on 5 interrelated components for explaining it: labeling, stereotyping, separating, emotional reactions and status loss/discrimination. Another conceptual model of stigma, which has been widely adopted by WPA, is that of the vicious circle of stigmatization, formulated by Sartorius ${ }^{9}$. According to this formulation, a marker that allows a person to be identified with it can be loaded with negative contents by association with previous knowledge. Once the marker is loaded, it becomes stigma and the individual who bears it, will inevitably be stigmatized, giving therefore rise to the establishment of a vicious circle. It is evident from the three conceptual frameworks that an emphasis is given on the constituent parts of stigma, namely stereotypes and prejudice, on the one hand and on its consequences on the other, namely discrimination and perpetuation of stigmatization. The unique feature of Link and Phelan's ${ }^{8}$ approach lies on the notion that stigma is based on social, financial and political leverage.

Most of the researchers have endeavored to develop valid and reliable tools for exploring existing conceptions and attitudes towards severe mental illness, after taking into consideration the prevailing ideology of their time. During the first half of the $20^{\text {th }}$ century, the instruments used were developed in line with the theoretical formulations of social distance ${ }^{10}$ and the authoritarian personality ${ }^{11}$, with the Custodial Mental Illness Ideology Scale by Gilbert and Levinson $^{12}$ echoing the spirit of California Scale. In early '60's, Cohen and Struening ${ }^{13}$ developed the widely used Opinion about Mental Illness scale (OMI), a 51-item instrument developed in two large psychiatric hospitals after aggregating the responses of 1.194 mental health professionals. The scale incorprorated item-statements from the scales of Adorno ${ }^{11}$ and Gilbert and Levinson ${ }^{12}$ focusing on aspects of custodial treatment and beliefs of devaluation; in particular that people with mental illness are unpredictable, childlike, incapable of making decisions, dangerous and in need of constant supervision. The aforementioned measures reflected the post war authoritarian social atmosphere towards mental illness and thus did not address contemporary issues, such as the social policy of deinstitutionalization and the heightened importance of genetic factors in the etiology of severe mental illnesses ${ }^{14}$. In addition, while the OMI scale sampled mental health professionals during its development and validation phase, it has been used in studies exploring lay attitudes. With the advent of community based care for people with severe mental illness, stigma scales had to switch their focus in order 
to address this new development in psychiatric care and the degree to which patients are accepted in the community. Congruent with this, Taylor and Dear ${ }^{15}$ developed the Community Attitudes towards Mental Illness (CAMI) scale, a modified version of the OMI scale. However three out of four factors: namely, Authoritarianism, Benevolence and Social Restrictiveness, were identical to those of the OMI scale ${ }^{16}$ and in line with this, the significant contribution of the scale is limited to the incorporation of the Community Ideology Mental Health factor. Since then, two scales have gradually gained ground in the measurement of mental illness stigma due to their potential to parallel the existing conceptual frameworks: the Perceived Devaluation - Discrimination Scale by Link $^{17}$ and the Attribution Questionnaire by Corrigan ${ }^{18}$. The Perceived Devaluation Discrimination assesses respondents' perception about what most people think of individuals with mental illness, entailing statements which tap the devaluation of psychiatric patients by others. The scale has been extensively used with service users, whereas not many studies have incorporated it in order to address public perceptions about mental illness. On the other hand, the Attribution Questionnaire is usually administered to members of the general population, after they have read a vignette describing a person with mental illness. The questionnaire assesses dimensions, such as personal responsibility, pity, anger, helping/avoidant behavior, and coercion-segregation and has displayed good psychometric properties $^{19}$.

In spite of the strengths of the existing measures, it seems that there is a gap in the literature with regard to the assessment of positive attitudes towards severe mental illness ${ }^{20}$. This is of great importance in the evaluation of anti-stigma initiatives, as the weakening of unfavorable attitudes is not necessarily translated into the strengthening of favorable ones. In line with this, an intervention aiming at promoting positive attitudes about severe mental illness should incorporate a measure that can tap these attitudes. It merits noting that while the OMI/CAMI scale "Benevolence" factor reflects a "sort of Christian kindness towards unfortunates"13, it is still a form of stigma, albeit a benign one. The disrespect inherent in the benevolence attitudes, according to which people with mental illness are perceived as children, cannot be confused with the genuine positive attitudes, where the person with mental illness is treated as equal.

In Greece, for the measurement of attitudes towards mental illness, the OMI scale was standardized and extensively used throughout the 1980's and 1990's in general population samples ${ }^{21,22}$ and health science students ${ }^{23-25}$. The only attitudinal study which has used the term "schizophrenia" was conducted by Economou and colleagues 26,27 in the context of WPA "Open the Doors" International Anti-Stigma Program.

Therefore, the aim of the study was to describe the rationale, methodology and psychometric properties of a new scale, which integrates elements of different conceptual frameworks on stigma, while updating current measurement literature by encompassing items tapping positive beliefs and attitudes. The term "severe mental illness" was chosen instead of schizophrenia due to the Greek origin of the term being linked to fear and devastation ${ }^{28-30}$.

\section{Methods}

The investigation of lay beliefs and attitudes to severe mental illness in Greece, was conducted by telephone interviews. The study was approved by the University of Athens 
Mental Health Research Institute Ethics Committee, in accordance to the provisions of Helsinki in 1995.

\section{Sampling}

Greece has a population of 11.3 million people in 4.3 million households and full telephone coverage consisting of 7.2 million residential lines. The sampling frame of the present study was the national phone number databank provided by the Organization of Telecommunications of Greece. Only telephone numbers belonging to individuals were included in the study. A random sample of telephone numbers -11 to 10,000 - belonging to individuals were selected. To be eligible for participation, respondents should have been between 18-70 years of age.

When more than one household member was eligible for interview, the participants were selected by utilizing a modified version of the Kish table. The sample was weighted according to gender, age and place of residence in line with the 2001 population census. With a $95 \%$ confidence limit, the maximum sampling error was $\pm 2.28 \%$.

\section{The interview}

The survey was carried out from May to June 2008 by a commercial company in the field of demographics surveys under the close guidance of the authors. Consistent with this, all interviews were conducted by 15 professionals, after they received a 26 hour training; including lectures, role playing and supervision of pilot interviews. After an oral informed consent was obtained from the participant, the interview was initiated.

\section{Measures}

Development of the Attitudes of Severe Mental Illness scale (ASMI)

After thoroughly reviewing the literature on mental illness stigma, a decision was made to develop an instrument suitable to capture contemporary thinking about stigma. The items drafted were grouped and discussed in two focus groups, one consisting of 12 lay people (six males and six females with a mean age $=48.5$ ) and another one consisting of five patients with severe mental illness ( 3 males and 2 females, mean age $=43.7$ ) and 5 family members ( 3 females and 2 males, mean age $=63.8$ ). These groups were coordinated by two mental health professionals of the research team.

Input from the focus groups resulted in 56 items being produced (first version), which were subsequently read by three mental health professionals, experts on community psychiatry. Professionals' contribution resulted in 45 items being included into the scale (second version). Ratings to each item were made on a four - point scale, ranging from "agree" (4) "rather agree" (3) "rather disagree" (2) "disagree" (1) "don't know" (0). Some item ratings were reversed in order to avoid acquiescence bias, while high scores suggested strong non stigmatizing opinions.

After the completion of 185 pilot telephone interviews on a general population sample (101 females and 83 males, mean age $=50.3, \mathrm{SD}=10.8)$, a third version of the scale was produced consisting of 35 items statements. Ten items were dropped on the grounds of low internal consistency (itemscale correlation $<0.3$ ) and enhancement of the Cronbach a upon their deletion (raising its value to be higher than 0.6). The third version of the scale was factor analysed. 


\section{Statistical analysis}

Student $t$ tests and ANOVA were used to test the differences in normally distributed numerical variables. Internal consistency of the scale was tested using Cronbach's alphas reliability coefficients ${ }^{31}$. Factor analysis was performed by the application of orthogonal (varimax) rotations method ${ }^{32,33}$ and Pearson correlations coefficients were computed to obtain results on the test retest reliability. Statistical analysis was performed using the Statistical Package for Social Sciences (SPSS) (v. 12.0).

\section{Results}

Out of the 2,788 responses to the calls, 2,039 were successfully interviewed (response rate: $73.1 \%$ ). People who refused to participate were not significantly different in terms of their gender, age and place of residence from people who took part in the study.

The socio demographic composition of the sample (Table 1) parallels the population census distribution of 2001, showing significant similarities.

\section{Validity}

The absence of a unanimously accepted "gold standard prompted us to evaluate the construct, face and predictive validity of the instrument.

\section{Construct validity}

A factor analysis of the 35-item scale, by using the principal component extraction method, was performed in order to explore the construct validity of the measure. "Don't know" responses constituted less than $1.2 \%$ of all answers and were excluded from the analysis.
Prior to performing the principal component analysis, the suitability of the data for factor analysis was assessed. A close look at the correlation matrix revealed that the value of many coefficients exceeded 0.3. The Kaiser - Meyer Olkin measure was 0.690 (> the limit of 0.6) and Bartletts test of sphericity was significant $(\mathrm{p}<0.01)$, justifying in this way the implementation of factor analysis. The Principal Component Analysis applying the Kaiser - Guttman rule for selecting factors (eigenvalues $>1.00$ ), yielded 4 components, explaining 32\%, 10\%, 16\% and $9 \%$ of the variance respectively. To assist with the interpretation of the findings, a Varimax rotation was used. In line with this, the four components explained $67 \%$ of the total variance and item communalities were found to be high. It is noteworthy that strong loadings (range from 0.39-0.66) were yielded for 30 items solely, and therefore five items were dropped.

The four ASMI scale four components are defined as follows:

- Component A: "Stereotyping" consisted of 11 items addressing commonly espoused negative conceptions of severe mental illness.

- Component B: "Optimism" encompassed 6 items, which addressed positive beliefs and attitudes about severe mental illness and patients.

- Component C: "Coping” entailed 7 items, which reflected strategies of coping with the illness and the stigma associated with it. It is noteworthy, that concealing the illness, hanging out with people with similar psychiatric disorders and avoiding other people loaded negatively on the component, implying in this way that concealing the illness and avoiding other people are different strategies from admitting the problem, not giving up, seeking help for it and relying on friends and families. 
Table 1

The social and demographic characteristics of the sample (n: 2,039) and the corresponding population census of 2001

Gender

Age

Population

Census 2001

\begin{tabular}{lrrrrr}
\hline Variants & $\mathrm{N}$ & $\%$ & $\mathrm{X}$ & $\mathrm{SD}$ & $\%$ \\
\hline Males & 1,013 & 49.7 & 41.50 & $(10.61)$ & 46.8 \\
Females & 1,026 & 50.3 & 43.71 & $(11.18)$ & 54.2 \\
Total & 2,039 & 100.0 & & & 100.0 \\
\hline
\end{tabular}

\section{Age groups}

$<24$

25-34

$35-44$

45-54

55-64

65-70

\section{Education in years}

$<11$

12

$>13$

\section{Marital status}

Single

446

224

10.9

9.2

407

20.0

19.8

290

14.2

16.2

416

20.4

19.4

345

16.9

16.0

357

17.6

18.4

Married

Widowed

1,724

22.2

21.0

,025

50.3

61.0

706

34.6

28.0

308

15.1

11.0

Divorced

95

70.4

70.0

74

3.8

6.0

3.0

\section{Occupational status}

Professional/ Business owners

$\begin{array}{rrr}63 & 3.0 & 3.0 \\ 87 & 4.3 & 6.0 \\ 270 & 13.3 & 11.0 \\ 604 & 29.6 & 26.1 \\ 324 & 15.9 & 20.0 \\ 352 & 17.3 & 15.1 \\ 61 & 2.9 & 4.0 \\ 256 & 12.6 & 14.8 \\ 22 & 1.1 & -\end{array}$

Employees/medium business owners

Clerks/small business owners

Skilled workers

Unskilled workers

Pensioners

$11-50,000$

14.0

Urban centers

15.8

44.6 
- Component D: "Understanding" comprised 6 items and described respondents' perceptions about how the person with severe mental illness feels or thinks about his/her illness: feeling inferior, responsible for causing burden to his/her family and for his/her illness and different from other people. In line with this, the items that loaded on the particular component address the extent to which the respondents can place themselves on the patients' shoes.

It is noteworthy that for Factors B, C, and $\mathrm{D}$ agreement implies non stigmatizing opinions and attitudes. On the other hand, agreement with the items of Factor A implies stereotypical beliefs and unfavorable attitudes. As a result of this, Factor A items were reversely scored by subtracting their rating from 5. In line with this, higher scores for all factors indicated non stigmatizing attitudes and opinions.

The factor analysis results are presented in Table 2.

\section{Face validity}

On a random sample of 80 adults, drawn from the original sample of 2,039, whose characteristics were similar, the interviewers read over the telephone the final version of the ASMI scale. Each respondent was asked to evaluate on a 6- point scale the appropriateness of each statement ( $1=$ absolutely unsuitable item, 2 = obviously unsuitable, $3=$ somehow unsuitable, $4=$ somehow suitable item, $5=$ obviously suitable, $6=$ absolutely suitable. For item mean values $<3$, the item was deemed unsuitable; however, respondents considered all 30 items to be suitable (mean scores ranging from 5.0 to 5.8).

\section{Predictive validity}

In order to assess this type of validity, the whole sample was divided into those respondents who were familiar with severe mental illness (n: 1,326) and those who were not (n: 700); while 13 people did not wish to disclose this type of information. Familiarity with severe mental illness was assessed via asking participants to indicate whether they know well a person who suffers from severe mental illness. Those who responded affirmatively showed higher mean scores for all factors of the scale in comparison to those who reported not knowing anyone with severe mental illness. Consistent with this, people who are familiar with severe mental illness appear to endorse fewer stereotypical beliefs about them, to be more optimistic about their course of illness and their capabilities, to support social openness as strategy for coping with the illness and to be in a better position to understand the feelings of the individual with severe mental illness. The scale therefore demonstrated a predicted pattern of results, lending support to its predictive validity (Table 3 ).

\section{Reliability}

\section{Internal consistency}

The scale in its final version was found to have very good internal consistency with the value of Cronbach's alpha being high $(\mathrm{a}=$ 0.88). Moreover, the internal consistency of the 4 components was satisfactory, with the corresponding Cronbach a ranging from 0.79 (factor C) to 0.86 (factor A).

\section{Test - retest reliability}

The final 30 items version of the scale was given to a random sample of 80 individuals. The telephone interviews were conducted twice in a week interval (test retest) following exactly the same procedure. Pearson's correlations coefficients between first and second interview for all components ranged from $r=0.89$ component $\mathrm{D}$ to $r=0.92$ for component A. 
Table 2

Factor analysis of ASMI scale: rotated component matrix and variance explained (n: 2,039)

Items

Factor A Factor B Factor C Factor D

1. If someone has experienced severe mental illness, he/she will suffer for the rest of his/her life

0.66

0.61

2. People with severe mental illness are failures

3. In spite of any efforts they are making, people with severe mental illness will never be like other people

4. People with severe mental illness have to take medication for the rest of their lives

0.61

0.54

5. Severe mental illness makes someone look ill $\quad 0.53$

$\begin{array}{ll}\text { 6. People with severe mental illness are not like any other people } & 0.51 \\ \text { 7. Severe mental illness is easily recognizable } & 0.51\end{array}$

8. People with severe mental illness are not able to acquire new skills

$\begin{array}{ll}\text { 9. People with severe mental illness are dangerous } & 0.43 \\ \text { 10. Severe mental illness is caused by bad luck } & 0.40\end{array}$

11. Psychiatric medication causes addiction $\quad 0.39$

12. A person with severe mental illness is able to work

13. A person with severe mental illness can be trained in an occupation responsible for his/her problem

\begin{tabular}{|c|c|c|c|c|}
\hline Variance & $32 \%$ & $10 \%$ & $16 \%$ & $9 \%$ \\
\hline
\end{tabular}

$\dagger$ Extraction method: Principal component analysis. Rotation method: Varimax.

Values $>0.39$ displayed.

Factor A: Stereotyping.

Factor B: Optimism.

Factor C: Coping.

Factor D: Understanding. 
Table 3

Predictive validity of the ASMI scale: Familiarity with a person suffering from serious mental illness and the ASMI scale factors mean scores (n: 2,026)

\begin{tabular}{lccccc}
$\begin{array}{l}\text { Knowing well someone with } \\
\text { severe mental illness }\end{array}$ & & Factor A & Factor B & Factor C & Factor D \\
\hline Yes & $\mathrm{N}$ & $\overline{\mathrm{X}}(\mathrm{SD})$ & $\overline{\mathrm{X}}(\mathrm{SD})$ & $\overline{\mathrm{X}}(\mathrm{SD})$ & $\overline{\mathrm{X}}(\mathrm{SD})$ \\
\hline No & 1,326 & 25.53 & 18.68 & 19.96 & 17.90 \\
& & $(7.59)$ & $(3.16)$ & $(2.30)$ & $(4.42)$ \\
\hline $\mathrm{t}$ & 700 & 24.23 & 17.83 & 19.18 & 16.92 \\
\hline P-value & & $(8.42)$ & $(3.92)$ & $(2.16)$ & $(4.40)$ \\
\hline
\end{tabular}

$\dagger$ t-test for independent samples, $\mathrm{df}=2,024$.

The results of internal consistency and test-retest reliability analysis are presented in Table 4.
The mean values of the ASMI scale factor scores by gender and place and residence are shown in Table 5.

Table 4

Internal consistency Cronbach's Alphas (n: 2,039) and Test-retest reliability results (n: 80)

\begin{tabular}{lcc} 
& Cronbach's Alpha & Test - retest \\
\hline & & Pearson coefficients \\
\hline Factor A (11) & 0.86 & $0.92^{*}$ \\
Factor B (6) & 0.82 & $0.86^{*}$ \\
Factor C (7) & 0.79 & $0.88^{*}$ \\
Factor D (6) & 0.80 & $0.89^{*}$ \\
\hline Total scale (30) & 0.89 & $0.94^{*}$ \\
\hline
\end{tabular}

$* \mathrm{P}<0.0001$.

Women expressed more stereotypical beliefs about severe mental illness and the people who suffer from it (lower mean scores in factor A subscale) in comparison with their male counterparts. In a similar vein, they were found to hold less favorable attitudes towards people with severe mental illness than men (lower mean scores in factor B). On the contrary, in factor C (coping) women were found to endorse to a greater extent that people with severe mental illness should be open about their illness. Similarly, women scored higher in factor D (understanding), indicating that they can understand better how a person with severe mental illness thinks or feels.

In terms of place of residence, a statistical significant effect was found only for the scores on factor A (stereotyping), with the residents of Athens area displaying fewer stereotypical beliefs than respondents from other regions. 
Table 5

Mean values of the ASMI scale factors A,B,C and D scores by the gender and place of residence (n: 2039)

\begin{tabular}{lccccc} 
& & Factor A & Factor B & Factor C & Factor D \\
\hline Gender & $\mathrm{N}$ & $\overline{\mathrm{X}}(\mathrm{SD})$ & $\overline{\mathrm{X}}(\mathrm{SD})$ & $\overline{\mathrm{X}}(\mathrm{SD})$ & $\overline{\mathrm{X}}(\mathrm{SD})$ \\
\hline Males & 1,013 & $25.8(8.4)$ & $18.3(3.8)$ & $18.9(2.8)$ & $16.6(4.8)$ \\
Females & 1,026 & $24.0(8.1)$ & $17.9(4.5)$ & $19.4(2.2)$ & $17.8(4.3)$ \\
$\mathrm{t}$ & $(\mathrm{df}=2,037)$ & $9^{* *}$ & $5.8^{*}$ & $3.7^{*}$ & $6^{*}$ \\
\hline
\end{tabular}

$\dagger \mathrm{t}$-test for independent samples, $* \mathrm{P}<0.001, * * \mathrm{P}<0.001$

\begin{tabular}{lccccc} 
Place of Residence & & Factor A & Factor B & Factor C & Factor D \\
\hline$<10,000$ pop & $\mathrm{N}$ & $\overline{\mathrm{X}}(\mathrm{SD})$ & $\overline{\mathrm{X}}(\mathrm{SD})$ & $\overline{\mathrm{X}}(\mathrm{SD})$ & $\overline{\mathrm{X}}(\mathrm{SD})$ \\
$11-50,000$ & 521 & $22.9(7.3)$ & $17.7(3.9)$ & $19.2(2.4)$ & $17.1(4.6)$ \\
$>50,000$ & 285 & $26.0(7.9)$ & $18.0(4.1)$ & $19.3(2.0)$ & $17.2(4.3)$ \\
Athens area & 322 & $26.2(9.0)$ & $18.1(4.2)$ & $19.1(2.3)$ & $17.5(4.5)$ \\
$\mathrm{F}$ & 911 & $27.8(8.6)$ & $18.1(4.2)$ & $19.6(2.4)$ & $17.6(4.4)$ \\
\hline
\end{tabular}

$\dagger$ One way ANOVA, $* \mathrm{P}<0.001$.

\section{Discussion}

The present study suggested that the ASMI scale has good psychometric properties. In terms of its validity, factor analysis revealed 4 dimensions to underlay the scale; namely, stereotyping, optimism, coping and understanding. The first factor entailed items describing stereotypical beliefs and attitudes to severe mental illness and the people who suffer from it. Items such as "people with severe mental illness are dangerous" or "are not like other people" constitute lingering perceptions about mental illness and have frequently appeared in stigma scales throughout the years. By contrast, the second factor appears to encompass items exuding a sense of optimism for people with severe mental illness. Patients' potential for recovery and their ability to acquire new skills are items included in this factor and fit well with scientific advances in the treatment of severe mental illness ${ }^{34}$. The third factor of the analysis was found to address respondents' beliefs and attitudes to the various coping strategies an individual with mental illness adopts in order to deal effectively with his/her illness and the stigma associated with it. The fourth factor addresses the stigma of mental illness indirectly, as it enquires about the ability of the respondent to understand how the individual with mental illness thinks and feels. The ability to think and feel like a person with mental illness can be regarded as a way of bridging the gap between the two groups involved in the separation process of stigma, the stigmatizing one and the stigmatized. This is in line with the view expressed by Cutler and colleagues $^{35}$ that empathy is situated at the opposite extreme of stereotyping and with evi- 
dence stemming from research on HIV stigma, which has linked enhancement of empathy with stigma reduction ${ }^{36}$. It merits noting that the items loaded on this factor were predominantly the items derived from the focus group with services users and their relatives during the scale development phase.

Interestingly, the factor structure of the scale fills in a gap in the existing literature of stigma measurement. Beliefs and attitudes articulated in a positive way were found to load on a similar factor, different from the one where beliefs and attitudes articulated in a negative way were grouped. This finding lends support to the claim that not endorsing negative attitudes is not synonymous to endorsing positive ones. If that was the case, then the items pertaining to these two factors would have loaded on a single dimension, with half of them displaying negative loadings and the other half displaying positive ones. Therefore, the finding that negative and positive attitudes constitute two separate entities highlights the importance of assessing them separately. This is of special concern in the context of antistigma interventions, where promoting positive attitudes to severe mental illness cannot be necessarily justified on the grounds of reducing stereotypical attitudes ${ }^{20}$. Furthermore, how participants respond and score to these two factors should trigger contemplation about the nature of stigma and the ways whereby people perceive individuals with severe mental illness. In particular, a respondent might score highly on the optimism factor and low on the stereotyping factor, manifesting in this way positive and negative attitudes concomitantly. This pattern of results might be due to the respondent's ambivalence and indecisiveness towards people with severe mental illness. It is a common place in Greek culture, to encounter lay people who are ambivalent about severe mental illness and report feelings of awkwardness and uneasiness in their presence ${ }^{37}$.

Alternatively, endorsing both positive and negative attitudes about severe mental illness might indicate that stigma is not a black or white phenomenon, with some people being stereotypical with regard to certain beliefs and attitudes and very accepting and positive with regard to patients' abilities and recovery potentials. Apart from the interesting findings concerning the factor structure of the scale, another of its strengths is its ability to integrate elements from the different conceptual frameworks of stigma. In particular, the item "people with severe mental illness are failures" is a devaluative statement and therefore it is in accordance with Link and Phelan's ${ }^{8}$ formulation. Similarly, the item "in spite of any efforts they are making, people with severe mental illness will never be like other people" describes succinctly the notion of separation and status loss found in the same theory. Items, which stress the importance of markers in triggering a vicious circle of stigmatization, for example "serious mental illness is easily recognizable" or "to be taking psychiatric medication does not make an individual different from others" are congruent with the conceptualization of mental illness stigma by Sartorius 9 . "Friends should not abandon a person when he or she is suffering from severe mental illness" captures well the concept of discrimination, whereas the statement "it is better to hide the problem to avoid life difficulties" denotes the long lasting strategy of concealing the illness for avoiding stigma and discrimination.

In terms of its reliability, the scale showed high internal consistency and good testretest reliability, lending further support to its use as reliable tool for measuring mental illness stigma. 


\section{Limitations}

This scale uses the term "severe mental illness" instead of a specific clinical diagnosis due to the close connection between the term "schizophrenia" and the feelings of fear and devastation ${ }^{28-30}$. In Greece, the word engenders confusion and despair due to its literal meaning (a "split mind"), and even mental health professionals avoid its use by replacing it with the term "psychotic syndrome" 27 . The general reference to "severe mental illness" might introduce unwanted variance among participants, stemming from differences in their interpretation of the word; nonetheless, the term "severe mental illness" has a more narrow scope than the term "mental illness" or "psychological problems". Alternatively, the study design could have incorporated a case vignette; however, the particular methodology is not popular in nationwide surveys ${ }^{26,27}$ and could have resulted in a low response rates and selection bias. Another limitation the analysis of the study did not elaborate on the socio-demographic correlates of the attitudes tapped by the scale, as emphasis was given on the presentation of its psychometric properties. Complementary findings will be presented in the near future.

\section{Conclusion}

In conclusion, the present study endeavored to develop a scale which combines elements from prevailing conceptual frameworks of mental illness stigma, while addressing existing gaps in its measurement. The investigation of its psychometric properties showed that the scale can be used as a reliable and valid tool for assessing positive and negative attitudes towards severe mental illness, while its factor structure spawned new research questions to be explored. There- fore, future work on the psychometric properties of the ASMI scale should investigate the sensitivity of the instrument to detect changes in attitudes following anti-stigma interventions.

\section{Acknowledgements}

The authors acknowledge the contributing unrestricted funding from Pfizer Pharmaceutical, Hellas, and the University of Athens Research Special Fund.

\section{References}

1. Corrigan PW. On the Stigma of Mental Illness: Practical Strategies for Research and Social Change. Washington: American Psychological Association; 2005.

2. Thornicroft G, Brohan E, Rose D, Sartorius N, Leese $\mathrm{M}$, et al. Global pattern of experienced and anticipated discrimination against people with schizophrenia: a cross-sectional survey. Lancet 2009; 373(9661): 408-415.

3. Thornicroft G. Shunned Discrimination against People with Mental Illness. New York: Oxford University Press; 2006.

4. Buizza C, Schulze B, Bertocchi E, Rossi G, Ghilardi A, Pioli R. The stigma of schizophrenia from patients' and relatives' view: A pilot study in an Italian rehabilitation residential care unit. Clin Pract Epidemiol Ment Health 2007; 3: 23-30.

5. Sartorius N. The World Psychiatric Association global programme against stigma and discrimination because of stigma. In: Crisp AH, ed Every Family in the Land. London: Royal Society of Medicine Press; 2004. p. 373-375.

6. Schulze B, Angermeyer MC. Subjective experiences of stigma. A focus group of schizophrenic patients, their relatives and health professionals. Soc Sci Med 2003; 56: 299-312.

7. Corrigan PW. Mental health stigma as social attribution: implications for research methods and attitudes change. Clin Psychol Sci Pract 2000; 7: 48-67.

8. Link BG, Phelan JC. Conceptualizing stigma. Ann Rev Soc 2001; 27: 363-385. 
9. Sartorius N. Breaking the vicious circle. Ment Health Learn Disabil Care 2000; 4: 80.

10. Bogardus EM. Measuring social distance. J Appl Sociol 1925; 9: 299-308.

11. Adorno TW, Frenkel-Brunswick E, Levinson DJ, Sanford RN. The Authoritarian Personality. New York: Harper; 1950.

12. Gilbert DC, Levinson DJ. Custodialism and humanism in staff ideology. In Levinson DJ, Williams RH, eds. The Patient and the Mental Hospital. Glencoe: Free Press; 1956.

13. Cohen J, Struening EL. Opinions about mental illness in the personnel of two large mental hospitals. J Abnorm Soc Psychol 1962; 64: 349-360.

14. Link BG, Yang LH, Phelan JC, Collins PY. Measuring mental illness stigma. Schizophr Bull 2004; 30: 511-541.

15. Taylor SM, Dear MJ, Hall GB. Attitudes toward the mentally ill and reactions to mental health facilities. Soc Sci Med 1979; 13: 281-290.

16. Dear MJ, Taylor MS. Scaling community attitudes toward mentally ill. Schizophr Bull 1981; 7: 225-240.

17. Link BG. Understanding labeling effects in the area of mental disorders: An assessment of the effects of expectations of rejection. Am Soc Rev 1987; 52: 96-112.

18. Corrigan PW. An attribution model of public discrimination toward persons with mental illness. J Health Soc Behav 2003; 44: 162-179.

19. Brown L. Factors and measurement of mental illness stigma: psychometric examination of the Attribution Questionnaire. Psychiatri Rehabil J 2008; 32: 89-94.

20. Corrigan PW, Shapiro JR. Measuring the impact programs that challenge the public stigma of mental illness. Clin Psychol Rev 2010; 30: 907-922.

21. Madianos M, Madianou D, Vlachonikolis J, Stefanis $\mathrm{CN}$. Attitudes towards mental illness in the Athens area: Implications for community mental health intervention. Acta Psychiatr Scand 1987; 75: 158-165.

22. Madianos M, Economou M, Hatjiandreou M, Papageorgiou A, Rogakou E. Changes in public attitudes towards mental illness in the Athens area (1979/1980-1994). Acta Psychiatr Scand 1999; 99: 73-78.

23. Arvaniti A, Samkouri M, Kalamara E, Bochtsou V, Bikos K, Livaditis M. Health service staff's attitudes towards patients with mental illness. Soc Psychiatry Psychiatr Epidemiol 2008; 43: 481-488.

24. Koutrelakos J, Gedeon S, Struening EL. Opinions about mental illness: A comparison of American and Greece professionals and laymen. Psychol Rep 1978; 43: 915-923.
25. Madianos M, Priami M, Alevisopoulos G, Koukia E, Rogakou E. Nursing students' attitudes towards mental illness and psychiatric case recognition after a clerkship in psychiatry. Issues Ment Health Nurs 2005; 26: 169-183.

26. Economou M, Gramandani C, Richardson C, Stefanis C. Public attitudes towards people with schizophrenia in Greece. World Psychiatry 2005; 4: 40-44.

27. Economou M, Richardson C, Gramandani C, Stalikas A, Stefanis C. Knowledge about schizophrenia and attitudes towards people with schizophrenia in Greece. Int J Soc Psychiatry 2009; 55: 361-371.

28. Madianos M. Changing the name of schizophrenia. Bull World Assoc Psychosoc Rehabil 2008; 19: 3-5.

29. Sugiura T, Sakamoto S, Tanaka E, Tomoda A, Kitamura T. Labeling effect of selshin - bunretsu - byou, the Japanese translation of schizophrenia: an argument for relabeling. Int J Soc Psychiatry 2001; 47: 43-51.

30. Sato M. Renaming schizophrenia. Japanese perspective. World Psychiatry 2006; 5: 53-55.

31. Cronbach L. Coefficient alpha and the internal structure of tests. Psychometrrika 1951; 16: 297-334.

32. Nunnaly JC, Bernstein IH. Psychometric Theory. New York: Mc Graw Hill; 1994.

33. Pett MA, Lackey NR. Extracting the initial factors. In: Pett MA, Lackey NR, Sallivan JJ, eds. Making Sense of Factor Analysis: The Use of Factor Analysis for Instrument Development in Health Care Research. Thousand Oaks CA. Sage 2003; 85-130.

34. Lysaker PH, Buck KD. Is recovery from schizophrenia possible? An overview of concepts, evidence, and clinical implications. Prim Psychiatry 2008; 15: 60-65.

35. Cutler JL, Harding KL, Mozian SA, Wright LL, Pica AG, Masters SR, et al. Discrediting the notion "working with 'crazies' will make you 'crazy"': addressing stigma and enhancing empathy in medical student education. Adv in Health Sci Educ 2009; 14: 487-502.

36. Brown L, Macintyre K, Trujillo L. Interventions to Reduce HIV/AIDS Stigma: What Have We Learned? AIDS Educ Prev 2003; 15: 49-69.

37. Economou M. Stigma and schizophrenia: The Greek experience. In: Maj M, Sartorius N, eds. Schizophrenia, Volume 2. Chichester: Wiley and Sons; 1999; 300-302.

Author for correspondence:

Professor Michael G. Madianos, Zografou

Community Mental Health Center, 42 Davaki-Pindou Street Athens 157-73, Greece

Tel: +30 2107481174

Fax:+30 2107718320

E-mail: madianos@nurs.uoa.gr 